\title{
WHO's work in relation to health and nutrition should counter the privatization agenda, but does it?
}

\author{
By Claudio Schuftan and Ted Greiner
}

Donor countries (the US in particular) continue to push WHO towards working with industry through 'multi-stakeholder partnerships', rather than giving WHO the chance to implement regulatory and financial strategies that could make a real difference. (David Legge-see acknowledgement below) This is part of a larger strategy to shrink public space and expand the power of the private sector (consisting almost exclusively of large corporations) at both domestic and international levels. This purely neoliberal political agenda has remained largely hidden by calling it something technical, the basis for 'increased efficiency', or by arguing that industry is the needed source of increased funding.

This same neoliberal agenda, as laid out in the US in the 1960s and 70s, at first sought to eliminate or at least greatly weaken the UN System in order to reduce government space and increase private sector space. This has gradually evolved into pushing the UN (and other actors in development assistance such as the large international NGOs) into accepting compromising support from or cooperation with the private sector. One major way of achieving this with respect to UN agencies has been to strangle their core funding while increasing the demands placed on them for effectiveness and efficiency. When UN agencies fail to achieve these demands, this is taken as 'proof' that they are ineffective and need to be 'reformed'. The same underlying agenda has involved

a) the freezing of assessed contributions by all member states (since about 1990 in many cases),

b) tight earmarking of unpredictable voluntary contributions that WHO receives for specific projects the funding institution or country prioritizes,

c) the creation of a growing dependence on private philanthropies' contributions,

d) periodic warnings that these funders will withhold their assessed contributions, and

e) continued pressure for the adoption of the multi-stakeholder partnership model of program and policy design and implementation.

All this gives bilateral donors, philanthropies and corporations, an unwarranted and risky 'seat at the table' especially dangerous when it comes to any issue that risks leading to regulating or otherwise reducing profit margins in global corporations. To what extent can and should the protection of human health and the environment take a back seat to profit-making? What is good for corporations is not, by definition, good for everyone as the neoliberal model insists.

The ongoing 'reform' of WHO is in fact simply a cover for speeding up this process. Similarly, the "reform" of the UN System Standing Committee on Nutrition was actually just an excuse for eliminating involvement by NGOs and civil society who repeatedly insisted the SCN avoid involving private sector actors, given their conflicting interests. 
A real reform, aimed at realizing the vision of WHO's Constitution, will require a global mobilization around the urgently needed democratization of global health and nutrition governance; and this is not separate from, but part of, a global mobilization for human rights and greater equality. Why? Because to claim that global health and nutrition governance is somehow independent of global economic and political governance, is not simply absurd. It plays into the hands of the neoliberal agenda, actually helping to obscure the vested interests and power relations at play that constrain interests-freedecision-making in WHO. (D. Legge)

Moreover, bilateral donors (as well as corporations and big philanthropies) demand WHO provides data according to their particular interests. Therefore, the types of data produced by WHO and other UN agencies (nutrition not an exception if one looks at the excessive attention paid to micronutrients, for example) are influenced by donor demands that go beyond the simple compilation of country-reported statistics. We know that these donors seek to add value primarily through providing technical interventions (and not human rights or the social determinants of ill health and malnutrition, for instance). The question is: Can WHO resist these pressures? (Elizabeth Pisani, Maarten Kok)

While economics is not WHO's core expertise, the impact of poverty and income maldistribution on population health and nutrition clearly justifies WHO working with other agencies within or outside the UN system to focus much more attention on the need for a reduction of disparity, not just on poverty. Even some of those who work with the IMF and the World Bank acknowledge that a) the processes that drive inequality are often the main drivers of poverty, and b) approaches that avoid tackling inequality are rarely effective.

Because of the decades long erosion of its core support, WHO's role in global health and nutrition governance has been shrinking. In its weakened and dependent state, the organization is increasingly being forced by rich member states into accepting 'multistakeholder platforms' and 'public-private partnerships' in a variety of policymaking roles, ignoring formerly accepted norms of conflict of interest. These same member countries have pushed WHO and other agencies into bundling together nationallevel public interest civil society organizations and social movements, international NGOs, private sector enterprises (and the NGO fronts they use), as well as philanthropies under the term 'non-state actors.' Also, the continued use of the purportedly neutral term 'stakeholders' ends up endowing private 'stakeholders' with having the same right to have a 'seat at the table' as organizations with only public health as their mandate--with only the tobacco and arms industries declared off limits. Such 'sitting rights' sharply jeopardize the human rights enshrined in the various human rights instruments that address the rights of real people--the_right to health and to nutrition prominently included. (D. Legge)

\section{WHO is burdened with a bureaucratic model inherited from the postwar era}

WHO actually seems strangely detached from the broader political turmoil unfolding around the world. Globalization has created new collective health and nutrition needs that cross old spatial, temporal and political boundaries. In response, we need global health and nutrition governance institutions that represent the many, not the few; that are sufficiently agile to act effectively in a fastpaced world, in addition to being capable of bringing together the best ideas and boundary-shattering knowledge available. (Kelley Lee)

WHO may point to its 193 member states and claim to be universally representative, but it is far from politically inclusive. Like the political alienation felt by millions around the world, many members of the 
global health and nutrition community have turned elsewhere to move issues forward and get things done. What we see is a weakening WHO under political pressure from external agents clinging to obsolete bureaucratic models, yet kept alive by member states that feel it is as an essential public institution. This decline is not because WHO is not needed, but because it has not been able to withstand these pressures and to adapt to a fast-changing world; added to this, its not being adequately financed by its member states. In short, it is not the WHO that we need today. (K. Lee)

For all the above reasons, political renewal must become a fundamental part of the process of WHO reform. Ponder, for instance:

- How could virtual and interactive town halls improve communication between global health policy-makers and the constituencies they purport to serve?

- How could the closed world of global policy-making be opened up and strengthened through virtual public consultations, feedback systems and monitoring systems --all of them also aiming at reforming $\mathrm{WHO}$ ?

- How could the concept of global citizenship become institutionalized within our global health institutions, especially WHO?

We are pleased to see that, if only very recently, WHO is beginning to do some of this (e.g., the UNSCN just sent out a letter inviting participation in a WHO consultation.) (K. Lee)

\section{Prescribing 'LEGO models'?}

In the first decade of the new millennium, many advocates pushed for increases in development assistance for health and for nutrition, but donor responses ended up mainly focusing on medicines and special manufactured foods --or isolated nutrients rather than improved diets. This is particularly true for the USA, that began purchasing HIV drugs, largely from its own drug industry, at full price to protect their patents and extreme over-pricing. This effectively side-tracked efforts to claim the HIV epidemic as an emergency, thus justifying the generic production of these drugs in heavily affected countries. If one thing has been constant in US development assistance, irrespective of the party in power, it has been adopting the policy put forward by President Calvin Coolidge when he said, "The business of government is business". Globally, we have witnessed a strengthening of intellectual property (patent) protection regimes with their well-known negative consequences for patients. Copyright protection has similarly been strengthened, with negative impacts on researchers in low-income countries.

Over the past decade, external funders have flocked to fund nutrient supplementation, food fortification, biofortification, and ready-to-use foods for the treatment and prevention of malnutrition. These are all highly technical, requiring outside expertise and either involving the importation of some components or purchase of intellectual property rights from the donor countries themselves. Unable to remain independent from the bilateral external funders (member states and the Gates Foundation that provide most of its funding), WHO has allowed its good offices to be used in furthering these vertical and product-oriented approaches. Although all UN agencies are pledged to apply the human rights framework, as well as addressing the different social dimensions of preventable ill-health and malnutrition, work towards the improvements of people's diets in the long term has clearly fallen into neglect. Moreover, US development assistance has intentionally been weak in the agricultural sector to enhance dependence on commodity imports from US farmers. For decades, as a tool to convince 
homegrown conservatives to support development assistance, food aid has aimed to create demand for crops such as wheat that cannot be grown in tropical climates.

Various development agencies are calling the mantra they preach to recipient countries 'realistic costing of outputs' which, in practice, prescribes 'a LEGO model of program implementation.' This means that each program ends up comprising a set of planned outputs each of which comprises a known number of prescribed activities, all of which have known costs. This approach leaves little, if any, room for flexibly managing complexity (in other words, learning from making mistakes), for acting creatively, or for responding to rapid changes happening on the ground. It also often standardizes a one-size-fits-all capacity building approach that hampers addressing the many other long-term needs. In addition, it prevents developing countries from learning the controversial art of choosing among competing priorities when planning and carrying out their program implementation. (D. Legge)

Furthermore, as is true for bilateral external funders, WHO has, more and more, been made wary of prolonged project implementation processes, in part because they 'disrupt the production schedule' demanded by its own paymasters. This allows the donors to decide, with little lead time, to change their priorities, without risking the bad press that can come from leaving critical long-term programs high and dry with no financing. (Elizabeth Pisani, Maarten Kok)

Meanwhile, no robust analysis is carried out of the root causes of the preventable global disease and preventable malnutrition burdens. Only this will provide clearer criteria regarding which 'stakeholders' (duty bearers in the proper human rights lingo) are part of the problem and which are part of the solution--and therefore which of them can be trusted to have a seat at the table. Human rights principles provide such criteria and so does the now ignored WHO report on Social (and political) Determinants of Health of 2008 (D. Legge)

As we all know, non-medical factors are widely recognized as being key predictors of good health and nutrition. In 2008, the WHO Committee on Social Determinants of Health stated: "Social injustice is killing people on a grand scale and constitutes a greater threat to public health than a lack of doctors, medicines or health care services". The general conditions under which people live and work have a major impact on health and nutrition outcomes. These social determinants of health and of nutrition also comprise the structural determinants of socioeconomic development such as working conditions, education, housing, sex and high-risk behaviors. What this implies for health is that health care (let alone medicines and nutritional products) is just one of the factors to influence health and can, therefore, only be considered part of the solution. (Koen Detavernier)

The influence/control of external funders over WHO and also over ministries of health in the South is nowhere more evident than in their interfering with UN agencies as they attempt to implement a human rights based approach beyond mere lip service. Instead, UN and ministry officials are bombarded with the newest slogans such as 'selective primary health care', 'scaling up nutrition', 'costeffectiveness', 'realistic costing of outputs', 'multistakeholder platforms' and 'public-private partnerships' that, in essence, are part of an agenda consistent with the program of the $1 \%$ richest. This often results in WHO and health ministries' speaking for the priorities of the $1 \%$, perhaps not realizing that they do so from within a worldview that accepts as natural and unchanging global inequalities, environmental degradation, and the beneficence of private enterprise. (D. Legge) 
The political renewal to ponder the questions asked above calls for, among other things, continuing the effort of the 'WHO Watch' that the People's Health Movement and other public interest CSOs are carrying out every January WHO Executive Board meeting and every May World Health Assembly (http://www.ghwatch.org/who-watch). The Watch systematically criticizes the above slogans of 'selective primary health care', 'scaling up nutrition', 'cost-effectiveness', 'realistic costing of outputs', 'multistakeholder platforms' and 'public-private partnerships' and intervenes in the discussion of every resolution the WHA tables, consistently bringing in the public interest positions depicted in this commentary --not least the WHO funding scandal.

\section{Acknowledgement:}

The authors acknowledge, as indicated throughout the text, that their commentary has been influenced by the writings of David Legge, Elizabeth Pisani, Maarten Kok, Kelley Lee and Koen Detavernier. (The reason for doing so has been to give credit where it was due, not to add credibility to our arguments. These ideas typically did not come from standard places one can reference).

\section{Suggested further reading}

1. WHO's deepening funding crisis was reviewed in the World Health Assembly of last May. WHO's core budget is ridiculously small in comparison with the needs it faces and its outcomes potential. The freeze on assessed contributions has caused donor dependence, tight earmarking, an inability to prioritize in any democratic way, and an inability to flexibly and rapidly respond to unexpected health emergencies. As the US delegate implied during the latest WHO Executive Board debate, WHO is being forced to shape its budget in accordance with donor preferences. "Donor dependence and frantic 'resource mobilization' also create major organizational dysfunctions: first, the divisive competition for donor attention across programs and regions and second, the loss of organizational coherence as the accountability of middle managers is directed to their donors rather than the organizational leadership. What is needed is a lift in the freeze on assessed (mandatory) contributions by member states and an increase in untied voluntary contributions." (See https://docs.google.com/document/d/1KTpdoQq5EkivAARV09KtGQev1H614DMbmVfB5Jjz7WI/edit )

2. Keep policy and priority setting free of commercial influence. Open letter to WHO Director General candidates published in: The Lancet http://www.thelancet.com/iournals/lancet/article/PIIS0140-6736\%2817\%2931146-7/fulltext

3. Corporate influence on the global health agenda: https://www.2030spotlight.org/sites/default/files/download/Spotlight2017_2_3_Gopakumar.pdf 